\title{
Fusion rates support wired allograft combined with instrumented craniocervical fixation in the paediatric population
}

\author{
Justus L. Groen ${ }^{1} \cdot$ Wilco C. Peul ${ }^{1,2} \cdot$ Willem Pondaag $^{1}$ \\ Received: 15 November 2019 / Accepted: 10 March 2020 /Published online: 24 March 2020 \\ (C) The Author(s) 2020
}

\begin{abstract}
Background Occipitocervical and atlantoaxial instability in the pediatric population is a rare and challenging condition to treat. Variable surgical techniques have been employed to achieve fusion. The study aimed to assess bony fusion with rigid craniocervical fixation using an allograft bone block to serve as scaffold for bony fusion.

Methods This is a single center case series from a tertiary referral neurosurgical center. The series includes 12 consecutive pediatric patients with rigid craniocervical fusion between 2006 and 2014 . The primary outcome was bony fusion as assessed by computed tomography and flexion-extension radiographs. The authors did not receive external funding for this study.

Results Twelve patients (age 1-15 years) were operated with a median imaging follow-up time of 22 months (range 6-69 m). A modified Gallie fusion technique with a tightly wired allograft bone block was used in 10 of 13 procedures. One patient underwent re-fixation due to screw breakage. Eleven out of 13 procedures resulted in a stable construct with bony fusion. All 10 patients operated with the modified Gallie fusion technique with sublaminar wiring of allograft bone block had bony fusion. No post-operative complications of the posterior fixation procedure were noted.

Conclusions The modified Gallie fusion technique with allograft bone block without post-operative immobilization achieved excellent fusion. We conclude there is no need to use autograft or BMPs in craniocervical fusion in the pediatric population, which avoids related donor-site morbidity.

Level of evidence Level IV_-case series; therapeutic.
\end{abstract}

Keywords Allograft · Bone fusion $\cdot$ Children $\cdot$ Craniocervical instability $\cdot$ Surgical technique

\section{Introduction}

Occipitocervical (OC) and atlantoaxial (AA) fusion in children may be indicated to treat craniocervical instability resulting from developmental, congenital, inflammatory, traumatic, and neoplastic disorders. Craniocervical instability in children is extremely rare, although in some subpopulations like children Down syndrome [18], the incidence of symptomatic atlantoaxial subluxation is relatively high at $1-10 \%$. Congenital occipitocervical instability may result from a

This article is part of the Topical Collection on Pediatric Spine

Willem Pondaag

w.pondaag@lumc.nl

1 Department of Neurosurgery, Leiden University Medical Center, PO Box 9600, 2300RC Leiden, The Netherlands

2 Department of Neurosurgery, Haaglanden Medical Center, The Hague, The Netherlands variety of bony or soft-tissue abnormalities, including condylar dysplasia, odontoid dysgenesis, and ligamentous laxity.

Without treatment, "deformity begets deformity" resulting in craniocervical kyphosis and progressive instability leading to nervous system damage by impingement of the high cervical spinal cord and brainstem. Tetraparesis, swallowing and breathing problems, and even sudden death might be the devastating outcome in this young population.

Over the last decades, variable surgical techniques have been employed to achieve fusion of the cranial-cervical junction in children. Generally, one can distinguish (1) non-rigid techniques like external fixation (halo-vest immobilization); (2) internal fixation using posterior wiring and onlay bone only; and (3) variable techniques of internal rigid fixation: occipital plate to $\mathrm{C}-1$ lateral mass screws and C-2 pars or pedicle screws (Harm's modified Goel technique), C-2 laminar screws, transarticular screw placement (Magerl technique), combinations [9] or unilateral occipital cervical fixation constructs. [14] These techniques all need supplemental 
bone onlay to promote fusion. Most authors employ autograft from patient's rib, iliac crest, or local bone, with or without addition of recombinant human bone morphogenetic protein (BMP) or bone marrow aspirate (BMA). The use of autograft in the pediatric population, however, may be limited due to the small size of harvest site. Besides that, harvesting of autograft will result in donor site morbidity, especially pain. In the present study, we describe a single center case series of rigid cranial cervical fusion using allograft instead of autograft.

\section{Materials and methods}

\section{Patient population}

All AA and OC fusions performed in consecutive pediatric patients in a 10 year cohort were reviewed in a tertiary referral clinic for complex spine conditions. The most common condition was a C1-C2 instability related to Down syndrome. All children except the one patient with a $\mathrm{C} 1$ fracture exhibited clinical pyramidal signs of spinal cord compression. Clinical data and details of surgery were gathered; clinical and radiological outcomes were retrospectively reviewed. All patients were subject to CT scan and if indicated a dynamic fluoroscopy at follow up. As this concerns a retrospective chart study, approval of the Medical Ethics Committee is not mandatory.

\section{Operative technique}

We did not employ neurophysiological monitoring. Internal rigid fixation was performed by the senior authors in all patients using a screw and rod system. When local anatomy allowed for placement of a screw in $\mathrm{C} 1$, this was the preferred treatment option. Either lateral mass screws were placed in $\mathrm{C} 1$, used in two patients (ID3 and ID12), or transarticular C1-C2 screws in three patients (ID2, ID3-r, ID10). If placement of a screw in $\mathrm{C} 1$ was considered unsafe due to small size of the $\mathrm{C} 1$ anatomy, a craniocervical construct was chosen, and the $\mathrm{C} 1$ arch was fastened to the rod with a titanium cable (8 patients). For C2 fixation, we used screw techniques depending on local anatomy: pars interarticularis screws (9/13), pedicle screws (1/13) (as defined by Benzel [5]), or transarticular screws (3/13), typically $3.5-4.5 \mathrm{~mm}$ in diameter and 12$18 \mathrm{~mm}$ in length. If indicated, a small-sized occiput plate was fixed on the planum nuchae using four bicortical screws close to midline and connected with titanium rods. In four patients (ID 6, 7, 9, and 10), instrumentation of C3 and $\mathrm{C} 4$ was performed.

We used a modified Gallie fusion technique. [23] Occipital bone surface, the posterior arch of $\mathrm{C} 1$, the $\mathrm{C} 2$ lamina, bilateral facet joints, and the spinous processes were decorticated with a high-speed drill before placing the allograft. Frozen allogeneic grafts were used as scaffold for bony fusion. Living donor femoral heads were employed, supplied by ETB-BISLIFE, a non-profit tissue institution (Galileiweg 8, Leiden, The Netherlands). A bone block was crafted to exactly fit the local anatomy using a bone rongeur and/or high speed drill. The monocortical bone block was carved from the femoral head, with a tight fit of the grafts spongious side to the posterior surface of the occiput and/or $\mathrm{C} 1$ posterior arch with a caudal notch to fit around the $\mathrm{C} 2$ spinous process. Using a Deschamps needle, a double titanium cable (Atlas Cable, Medtronic, Minneapolis, USA) was passed sublaminarly under the C1 arch (Fig. 1). Sublaminar wires under the $C 2$ arch were not employed. In most patients, both cables were additionally guided around the rods of the screw and rod system bilaterally after which the cables were tensioned and crimped (Fig. 2). In this fashion, the $\mathrm{C} 1$ arch could be retracted posteriorly if indicated, and the resulting construct was considered stiffer including also C1 (Fig. 3). The cable was subsequently passed over the cortical side of the onlay bone block. Once the graft was tightly placed, the titanium cable was tensioned to 35 pounds and crimped on top of the bone block. Around the bone block graft, morcellized spongious graft was deposited, obtained from the remainder of the femoral donor head. In patient ID3, sublaminar wiring was not employed during the first surgical procedure, as the bone block seemed tightly fit between the occiput and $\mathrm{C} 2$ spinous process without wiring. In another two procedures (ID1 and ID2), only morcellized graft was inserted. Autologous bone marrow aspirate, aspirated from the patient's iliac wing, was applied around the graft material in 4 patients. BMPs were not used (Table 1).

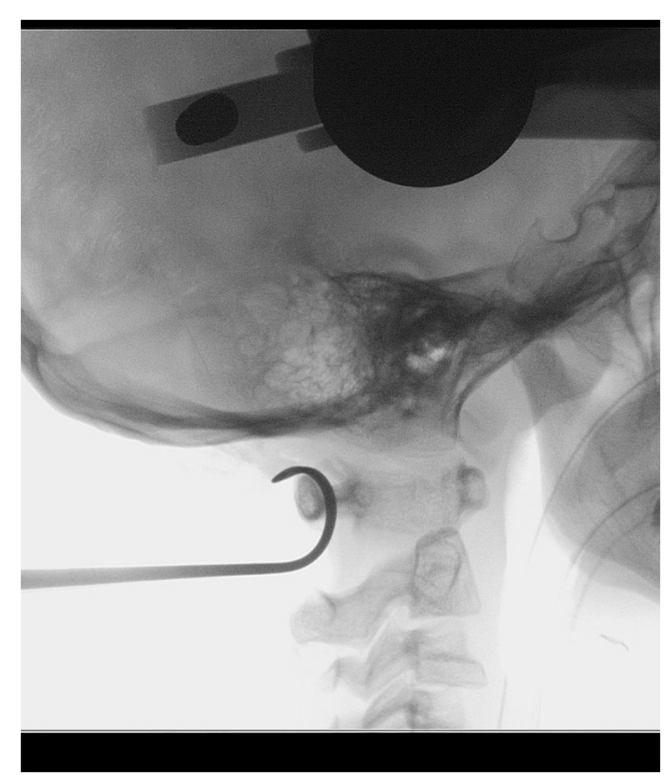

Fig. 1 Fluoroscopy showing a Deschamps needle passed under the C1 arch to place a sublaminar wire 




Fig. 2 Drawing of the fusion technique. Frequently, the construct consisted of a $\mathrm{C} 2$ screw and an occiput plate. Before the rod-and-screw construct was put into place, a titanium cable was put around the $\mathrm{C} 1$ arch laterally on both sides. The titanium cable was wrapped around the rod, tightened, and crimped bilaterally with the system connector. The surface

\section{Assessment of fusion}

Patients underwent standard clinically examination at 8 and 26 weeks post-operatively. For confirmation of fusion, computed tomography was performed in all patients and flexion-extension radiographs of the cervical spine if indicated. Fusion was defined as cortical union of the allograft and central trabecular continuity as proof for a complete bony bridge [22] between the posterior arch of $\mathrm{C} 2$ and the occiput (OC fusion) or posterior arch of $\mathrm{C} 1$ (AA fusion). The fusion was assessed independently from radiologists by the senior authors. Once bony fusion was ascertained, this was defined as radiological endpoint, and no more CT scans were obtained. b

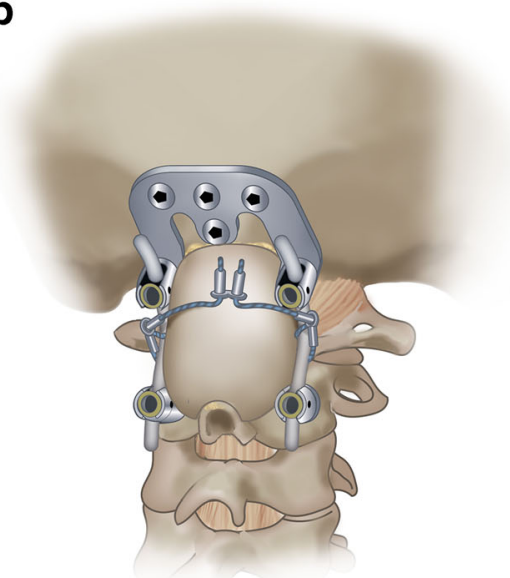

of the occiput, the $\mathrm{C} 1$ arch, and the $\mathrm{C} 2$ arch were partially decorticated with a high speed drill. The crafted bone graft was placed with good contact to the occiput, the $\mathrm{C} 1$ arch and, the $\mathrm{C} 2$ arch and spinous process, with the cortical surface posteriorly. The cable ends were then passed over the graft, tightened, and crimped using a double connector, and cut short

\section{Results}

\section{Baseline characteristics}

We identified twelve pediatric patients with craniocervical instability who were treated with rigid posterior fixation and operated between 2006 and 2014. Mean age at surgery was 9.7 years (range $1-15$ years), $25 \%$ of patients was female. All but one patient were over 5 years of age. All patients had instability of the $\mathrm{C} 0-\mathrm{C} 1-\mathrm{C} 2$ segment either as a direct result of their condition, or instability existed after surgery (e.g., tumor resection or transoral odontoid resection). Ten patients suffered from congenital malformations of the craniocervical junction: three in Down syndrome (with os odontoideum in one), two patients diagnosed with spondyloepiphyseal


Fig. 3 Fluoroscopy of patient ID-8. a/b Pre-operative ante-position of $\mathrm{C} 1$, mobile segment with posterior movement of $\mathrm{C} 1$ in extension. $\mathbf{c}$ Post-operative alignment of $\mathrm{C} 1$ after wiring of $\mathrm{C} 1$ arch and bilateral rods 


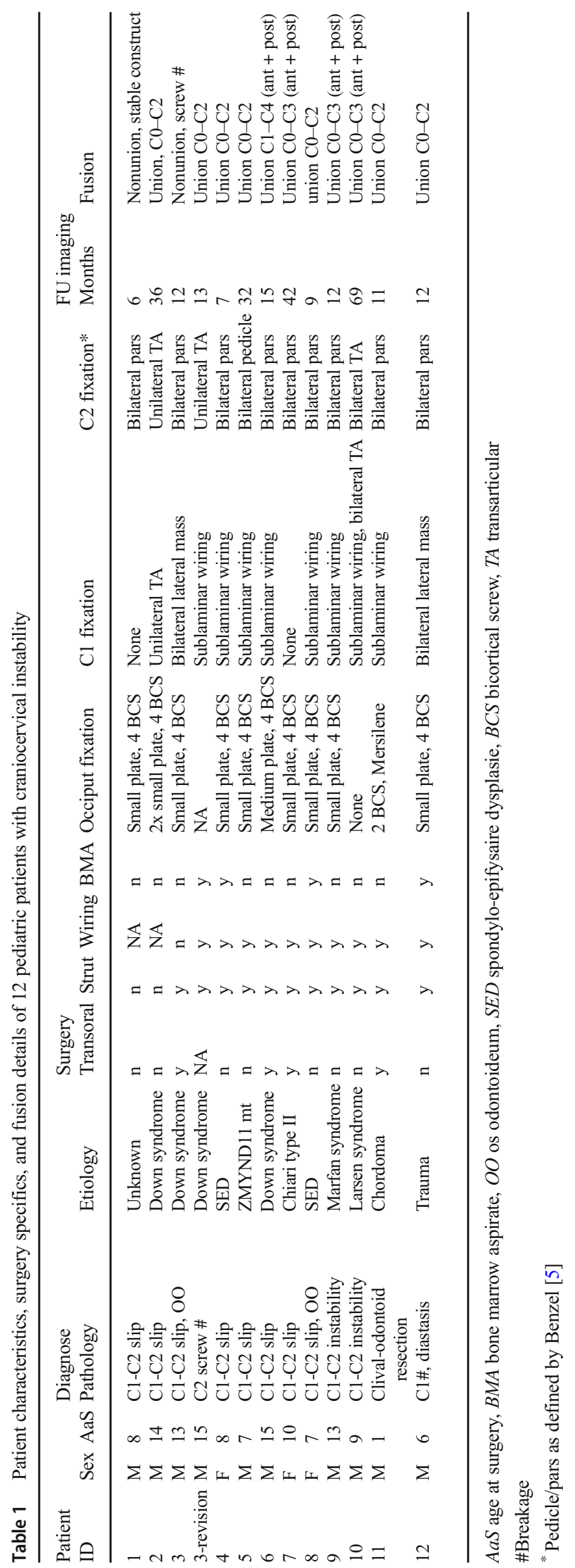


dysplasia congenital (SED), and the other patients were diagnosed with Larsen syndrome $(n=1)$, Marfan syndrome $(n=$ 1), Arnold Chiari syndrome type $2(n=1)$, a syndrome caused by a de novo mutation in ZMYND11 [6] $(n=1)$, and a syndrome of unknown origin $(n=1)$. Two remaining cases suffered of acquired junctional instability: one due to traumatic fracture of $\mathrm{C} 1$ and one after transoral resection of a skull base chordoma. Transoral anterior decompression preceding the OC fixation was performed in 4 patients.

Median follow up imaging was 22 months (range 6-69 m). No post-operative complications of the posterior fixation procedure were noted. Median duration of admission was 6.6 days (range 4-11). Restriction of cervical motion by collar or halo frame in the post-operative period was not applied.

\section{Fusion rate}

In the present cohort, 11/13 procedures resulted in a stable bony fusion; all primary surgeries that included a tightened wiring of allograft bone block resulted in bony fusion. Two of 13 occipitocervical fusion procedures resulted in a non-union $(15 \%)$. Both non-unions occurred in patients without a wired bone block graft: patient ID3 showed a unilateral C2 screw breakage at follow-up imaging after 16 months as a result from persistent instability. A re-fixation was performed with allograft bone block, sublaminar wiring, and application of bone marrow aspirate, eventually resulting in a solid anterior and posterior $\mathrm{C} 0-\mathrm{C} 2$ fusion. In patient ID1, no bone block was placed. On follow-up imaging at 6 months, a stable position of the $\mathrm{C} 1-\mathrm{C} 2$ segment was seen, however, no bony union. Flexion-extension fluoroscopy shows no movement at followup time of 3 years; therefore, no re-intervention was indicated.

\section{Discussion}

Bony fusion was achieved in all 10 children with craniocervical instability treated with a modified Gallie fusion technique using tightly wired allograft bone blocks. The two failures of fusion occurred in those two patients in whom such wired bone blocks were not employed. Based on this series, it is fair to conclude that there is no need to use autograft for craniocervical fusion in children, which avoids the post-operative donor-site pain and morbidity. Additionally, using rigid screw and rod fixation, post-operative immobilization is not needed, facilitating early rehabilitation. Although there has been some debate among spine surgery experts about the use of bone graft in craniocervical fixation, the current series with 2 failures by not using bone graft and our experience with pseudo-arthrosis in the adult population mandates the use of bone graft.

Limitations of the present study are the following: (1) our patient series is relatively small and includes diverse underlying pathology. This reflects the rareness of the indication for AA or
OC fusion in the pediatric population. As our main outcome parameter was bony fusion, as the most appropriate outcome measure for the described surgical technique, we feel that the difference of the underlying pathology is not relevant. (2) In four patients, follow-up was less than 1 year, which is generally considered a minimum for reporting patient outcome. We consider, however, that once bony fusion has been demonstrated, that such can be regarded as irreversible end stage: the patient will not "unfuse." Thus, for the current purpose to demonstrate the effectiveness of an allograft bone block to ensure bony fusion, the follow-up in our series can be considered adequate.

The use of allograft bone has several advances over autograft, especially in the pediatric population. Morbidity from autograft harvest site are well documented and frequent (9\%), including post-operative pain, increased blood loss, increased infection risk, seroma formation, pelvic fracture, the risk of peripheral nerve injury, and donor site pain. Moreover, it is a challenge to harvest and craft a well-fitting bone block from a small costa or thin iliac crest in children. [8, 19, 21] Allografts are only osteoconductive, weakly osteoinductive, but not osteogenic like autografts; therefore, their use in posterior fixation is associated with a higher rate of nonunion. [4] An older publication by Koop et al. (1984) noted that pseudoarthrosis occurred in one patient who received allograft instead of autograft in their pediatric OC fusion procedures, strengthening this author's view that autograft is superior in fusion. [12] In a recent meta-analysis on OC fusion in children, a strong surgeons' preference for the use of autologous bone was shown, as it had been used in 539 pediatric cases compared with only 65 children where allograft had been employed using various fixation techniques. Higher fusion rates were seen with autologous bone graft compared with allograft (97\% vs $85 \%$ ). However, in a subgroup analysis for rigid internal fixation techniques including only 18 patients from 5 different studies where allograft was used, the differences were smaller (99\% vs 94\%, respectively). [19] In an adult population, Godzik and colleagues reported in adult population bony OC fusion in allograft group in 18 of $19(95 \%)$ and 8 of $8(100 \%)$ in the autograft group after a minimum of 12-month follow-up. [8]

To overcome the lack of osteoinductive function of allograft, the use of bone marrow aspirate (BMA) [15] or bone morphogenetic proteins (BMP) are advocated. Some case series in lumbar fusion in adults suggest that addition of BMA on an allograft scaffold might improve bony fusion [11, 16, 24], however, as yet no studies in cervical posterior fixation in children are available. In our series, we used BMA on the site of fusion in 4/13 procedures. BMP is routinely employed in most reports of $\mathrm{OC}$ and posterior cervical fusion in adults with allograft. However, in a recent meta-analysis, Reintjes et al. did not find a statistically significant association of BMP with successful fusion in any of the univariate or multivariate analyses. [19] Sayama also concluded there is no need for routine use of recombinant BMP in the pediatric age group. [20] 
Based on our current findings and the literature, we do not consider application of BMP to be essential for fusion if rigid fixation is achieved.

Essential for fusion is an adequate fit of the onlay bone block and proper surgical preparation of the posterior surfaces for optimal bone-to-bone contact. A second requisite for fusion is mechanical stress on the bone-to-bone surface, aka as Wolff's law. [2] With rigid fixation, there is a risk that the bone is shielded from mechanical stress by the stiffness of the screw and rod system, which may result in resorption of the graft. [17] In this series, we described the use of allografts tailored to fit between the occiput or the $\mathrm{C} 1$ arch and $\mathrm{C} 2$ spinous process and compressed with tensioned wiring around the lateral rods, the $\mathrm{C} 1$ arch and/or the $\mathrm{C} 2$ spinous process. We believe that tensioning of the graft is essential to achieve bony fusion. On this account, we show with the present series that fusion rates are excellent by using the described technique. For sublaminar wiring, the Deschamps needle [7] proved to be a very useful instrument.

Some authors reserve rigid instrumentation for children above 5 years of age, or even above 10 years, based on report on abnormal cervical spine growth in children who underwent craniocervical stabilization at young age. $[1,3,10]$ In our series, six patients underwent surgery under the age of 10 years, and all showed bony fusion and no growth difficulties (mean follow-up interval 22.5 months), suggesting that internal rigid fixation is feasible in this population too. In these very young children, the surgical challenge can be considered substantially more profound than in children above 10 years. The youngest patient was a 1-year-old boy (ID11) in whom we performed a $\mathrm{C} 0-\mathrm{C} 2$ fixation after transoral clival chordoma resection. At follow-up imaging at 11 months, there was bony fusion in adequate position. Follow-up may be too short to appreciate growth abnormalities in some of the patients in present series; however, Martinez-del-Campo and colleagues described normal growth, curvature, and alignment parameters in their series of children with OCF constructs. [13] The retrospective nature, the small number of patients and single center character of this cohort study make it uncertain that our results can be extrapolated to all pediatric patients who need a craniocervical fusion. We feel, however, to have made a strong argument in favor of the described technique.

\section{Conclusion}

This report on surgical strategy differs from other reports on craniocervical fusion in the pediatric population. With the presented modified Gallie fusion technique using allograft (instead of autograft) bone block and compressed wiring technique (both wiring to the fixation rods and sublaminar wiring), we achieved a rigid construct and excellent $\mathrm{AA}$ and $\mathrm{OC}$ fusion rates. Both the use of BMPs and post-operative external immobilization are not indicated in these children.

\section{Compliance with ethical standards}

Conflict of interest Justus Groen declares that he has no conflict of interest; Prof Wilco Peul received research grants from Medtronic for other studies, not-related to the current subject; Willem Pondaag declares that he has no conflict of interest.

Research involving human participants All procedures performed in studies involving human participants were in accordance with the ethical standards of the institutional and/or national research committee and with the 1964 Helsinki declaration and its later amendments or comparable ethical standards.

Informed consent Informed consent for treatment was obtained from all individual participants included in the study. Under Dutch legislation, there is no informed consent needed for the retrospective analysis of patient series to be published anonymously.

Open Access This article is licensed under a Creative Commons Attribution 4.0 International License, which permits use, sharing, adaptation, distribution and reproduction in any medium or format, as long as you give appropriate credit to the original author(s) and the source, provide a link to the Creative Commons licence, and indicate if changes were made. The images or other third party material in this article are included in the article's Creative Commons licence, unless indicated otherwise in a credit line to the material. If material is not included in the article's Creative Commons licence and your intended use is not permitted by statutory regulation or exceeds the permitted use, you will need to obtain permission directly from the copyright holder. To view a copy of this licence, visit http://creativecommons.org/licenses/by/4.0/.

\section{References}

1. Ahmed R, Traynelis VC, Menezes AH (2008) Fusions at the craniovertebral junction. Childs Nerv Syst 24(10):1209-1224

2. Anand N (2016) Overview of biologics. Spine (Phila Pa 1976) 41(Suppl 7):S10

3. Anderson RCE, Kan P, Gluf WM, Brockmeyer DL (2006) Longterm maintenance of cervical alignment after occipitocervical and atlantoaxial screw fixation in young children. J Neurosurg 105(1 Suppl):55-61

4. Aurori BF, Weierman RJ, Lowell HA, Nadel CI, Parsons JR (1985) Pseudarthrosis after spinal fusion for scoliosis. A comparison of autogeneic and allogeneic bone grafts. Clin Orthop Relat Res 199:153-158

5. Benzel EC (1996) Anatomic consideration of C2 pedicle screw placement. Spine (Phila Pa 1976) 21(19):2301-2302

6. Cobben JM, Weiss MM, van Dijk FS, De Reuver R, de Kruiff C, Pondaag W, Hennekam RC, Yntema HG (2014) A de novo mutation in ZMYND11, a candidate gene for 10p15.3 deletion syndrome, is associated with syndromic intellectual disability. Eur $\mathrm{J}$ Med Genet 57(11-12):636-638

7. Di Lorenzo N, Coscarella G, Lirosi F, Gaspari A Port-site closure: a new problem, an old device. J Soc Laparoendosc Surg 6(2):181183

8. Godzik J, Ravindra VM, Ray WZ, Schmidt MH, Bisson EF, Dailey AT (2015) Comparison of structural allograft and traditional autograft technique in occipitocervical fusion: radiological and clinical outcomes from a single institution. 23(August):144-152

9. Hankinson TC, Avellino AM, Harter D et al (2010) Equivalence of fusion rates after rigid internal fixation of the occiput to $\mathrm{C}-2$ with or without C-1 instrumentation. J Neurosurg Pediatr 5(4):380-384 
10. Kennedy BC, D'Amico RS, Youngerman BE et al (2016) Longterm growth and alignment after occipitocervical and atlantoaxial fusion with rigid internal fixation in young children. J Neurosurg Pediatr 17(1):94-102

11. Kitchel SH (2006) A preliminary comparative study of radiographic results using mineralized collagen and bone marrow aspirate versus autologous bone in the same patients undergoing posterior lumbar interbody fusion with instrumented posterolateral lumbar fusion. Spine J 6(4):405-411

12. Koop SE, Winter RB, Lonstein JE (1984) The surgical treatment of instability of the upper part of the cervical spine in children and adolescents. J Bone Joint Surg Am 66(3):403-411

13. Martinez-Del-Campo E, Turner JD, Soriano-Baron H, Newcomb AGUS, Kalb S, Theodore N (2016) Pediatric occipitocervical fusion: long-term radiographic changes in curvature, growth, and alignment. J Neurosurg Pediatr 18(5):644-652

14. Mazur MD, Ravindra VM, Brockmeyer DL (2015) Unilateral fixation for treatment of occipitocervical instability in children with congenital vertebral anomalies of the craniocervical junction. https://doi.org/10.3171/2015.1.FOCUS14787.Disclosure

15. Muschler GF, Nitto H, Matsukura Y, Boehm C, Valdevit A, Kambic H, Davros W, Powell K, Easley K (2003) Spine fusion using cell matrix composites enriched in bone marrow-derived cells. Clin Orthop Relat Res 407:102-118

16. Neen D, Noyes D, Shaw M, Gwilym S, Fairlie N, Birch N (2006) Healos and bone marrow aspirate used for lumbar spine fusion. Spine (Phila Pa 1976) 31(18):E636-E640

17. Pilitsis JG, Lucas DR, Rengachary SS (2002) Bone healing and spinal fusion. Neurosurg Focus 13(6):e1
18. Pueschel SM, Scola FH, Perry CD, Pezzullo JC (1981) Atlantoaxial instability in children with down syndrome. Pediatr Radiol 10(3):129-132

19. Reintjes SL, Amankwah EK, Rodriguez LF, Carey CC, Tuite GF (2015) Allograft versus autograft for pediatric posterior cervical and occipito-cervical fusion: a systematic review of factors affecting fusion rates. J Neurosurg Pediatr 1-16

20. Sayama C, Willsey M, Chintagumpala M, Brayton A, Briceño V, Ryan SL, Luerssen TG, Hwang SW, Jea A (2015) Routine use of recombinant human bone morphogenetic protein-2 in posterior fusions of the pediatric spine and incidence of cancer. J Neurosurg Pediatr 16(July):1-10

21. Schultz KD, Petronio J, Haid RW, Rodts GE, Erwood SC, Alexander J, Naraad C (2000) Pediatric occipitocervical arthrodesis. A review of current options and early evaluation of rigid internal fixation techniques. Pediatr Neurosurg 33(4):169-181

22. Tan GH, Goss BG, Thorpe PJ, Williams RP (2007) CT-based classification of long spinal allograft fusion. Eur Spine J 16(11):18751881

23. Vender JR, Rekito AJ, Harrison SJ, McDonnell DE (2004) The evolution of posterior cervical and occipitocervical fusion and instrumentation. Neurosurg Focus 16(1):E9

24. Yamada T, Yoshii T, Sotome S et al (2012) Hybrid grafting using bone marrow aspirate combined with porous $\beta$-tricalcium phosphate and trephine bone for lumbar posterolateral spinal fusion. Spine (Phila Pa 1976) 37(3):E174-E179

Publisher's note Springer Nature remains neutral with regard to jurisdictional claims in published maps and institutional affiliations. 